\title{
UNDERSTANDING FAMILY PLANNING PRACTICES AMONG RURAL TRIBALS OF DIBRUGARH DISTRICT. ASSAM.
}

Nabanita Nirmolia, Alak Barua

1. Assistant Professor, Department of Community Medicine, Assam medical College, Dibrugarh.

2. Professor, Department of Community Medicine, Assam medical College, Dibrugarh.

\section{CORRESPONDING AUTHOR}

Dr Nabanita Nirmolia.

C/O K C Nirmolia

Gandhinagar, Huwoni Poth,

Dibrugarh, Assam

E-mail: nabanitanirmolia@yahoo.com

Ph: 00919435130507

ABSTRACT: RESEARCH QUESTION: What is the extent of use of family planning practices and what are the factors influencing the methods of contraception? OBJECTIVE: To find out the distribution of family planning practices with respect to literacy, age and reasons for not practicing any method. STUDY DESIGN: Community Based Cross sectional study. MATERIALS \& METHODS: Multistage sampling technique was used to select the sample. Villages were selected by stratifying them according to the presence of tribal and non tribal population. Thereafter the tribal dominated villages were selected at random and house to house visit was made. A total of 303 married women in the age group of 15-45 years living with their spouses were interviewed using a pre designed questionnaire. Chi square test was used for the analysis. Results: Couple Protection Rate is $29.7 \%$. Acceptance of family planning methods is associated with education of husbands and increase in age of wives.

Conclusion: Family planning practices is observed to be poor amongst the tribals and therefore motivation of the couples is to be stepped up.

KEY WORDS: Eligible couple, family planning, couple protection rate.

INTRODUCTION: With a population of 1027 million$^{1}$, according to Census 2001, India is witnessing the phenomenon of population explosion. Keeping in view of the increasing population growth rate it has become an utmost necessity to limit the family size which can be achieved by practicing the different family planning methods.

An Expert Committee(1971) of WHO defined Family Planning as "a way of thinking and living that is adopted voluntarily, upon the basis of knowledge, attitudes and responsible decisions by individuals and couples, in order to promote the health and welfare of family group and thus contribute effectively to the social development of a country"2.

For centuries, Assam is inhabited by people belonging to different caste and creed, races and ethnic groups and the tribals constitute one such group. The National Population Policy 2000 gave special emphasis on the urgency of their upliftment.

According to The Office of the Registrar General, India, 2001 census $^{3}$, the Total Fertility Rate of Scheduled Tribes in rural area is 3.26 , which work out to be higher in comparison to 2.83 of the total rural population.

Keeping the above points in mind the present study was undertaken in a rural tribal community. 
METHODOLOGY: The present study was carried out in the tribal dominated villages under Borboruah Block of Dibrugarh District from July2007 to June 2008. The Block is situated at a distance of $12 \mathrm{Kms}$ away from Dibrugarh town. The total tribal population of the Block is reported to be 24,294 .

The study population comprised of eligible couples with the wives in the age group of 15-45 years.

The sample size was calculated using the formula $n=z^{2} p q / L^{2}$ where $z=1.96, p$ is the positive character, $\mathrm{q}=1-\mathrm{p}, \mathrm{L}$ is allowable error.

In Assam, 27\% of the currently married women of reproductive age group are protected against conception (NFHS 3, 2005-2006). So considering $p=0.27$ and allowable error at $5 \%$, the sample size for the present study is calculated to be 303. Multistage sampling technique was used for selection of the sample. At the first stage, out of the 6 Blocks of Dibrugarh, Borboruah Block was selected because $27.5 \%$ of the total Scheduled Tribe population of the district is present in this Block, which is quite a significant number. Secondly villages were selected by stratifying them according to the presence of tribal and non tribal communities. Of all the villages only tribal dominated villages were selected which were 30 in number. The tribal dominated villages were randomly selected for the study. The interview was taken by house to house visit. Since the required sample size was not fulfilled in the first village, so another two villages were randomly selected and thus a total of three villages were visited to get the required sample size.

The three villages chosen for the study were Dulia Gaon, Lalmati Tinsukia and Notun Bolai Gaon situated at a distance of $3 \mathrm{kms}, 18 \mathrm{kms}$ and $18 \mathrm{kms}$ respectively from Borborua PHC of which Dulia Gaon and Notun Bolai gaon becomes non motorable during the summer season because of rains. The main occupation of the people is cultivation. Some of the families have access to newspapers and Television, but are ignorant of the different services being delivered at a health facility.

In the PHC, there is provision of counseling and prescribing OCP and barrier methods, but as there are no specialists, hence the beneficiaries need to visit Assam Medical College, a tertiary care centre for Intrauterine devices and terminal methods. The distance from the villages to Assam Medical College is $15 \mathrm{kms}, 30 \mathrm{kms}$ and $30 \mathrm{kms}$ respectively.

Chi square test was used for the analysis.

RESULTS: The study was conducted amongst the eligible couples with wives in the age group of 15-45 years of Borboruah Block in Dibrugarh District of upper Assam. Couples with pregnant wives were excluded from the study.

Table1 shows that only $29.7 \%$ practiced approved methods of family planning.

Table 2 reveals that none of the husbands underwent vasectomy.

In Table 3 significant association was observed between the practice of family planning methods and educational status of the husbands up to high school and higher education.

Table 4 reveals that the acceptance of family planning method is significantly associated with increase in age of wives. 
Table 5 showed that the reasons for never practicing any methods of family planning were lack of information in $22.89 \%$ of the couples, $22.38 \%$ couples wanted children and $20.9 \%$ were afraid of side effects.

DISCUSSION: The couple protection rate was $29.7 \%$ in the present study. In another study Mohanan P. et al (2003) recorded a couple protection rate of $28.1 \% 4$.

In the study, vasectomy was not practiced by any of the male partners which corroborates with the findings of Reddy R. et al (2003) ${ }^{5}$ and Puri A. et al (2004) ${ }^{6}$

Chandhick N. et al(2003) at their study revealed that since in rural areas husbands are the decision makers ${ }^{7}$, their approval is strongly associated with acceptance of family planning practices. Aggarwal H. et al (2005) observed that the education of husbands were related to the use of contraceptive methods ${ }^{8}$. The present study revealed that acceptance of family planning method increases with increase in educational status of the husbands up to high school and above. $(\mathrm{p}<0.05)$

The present study showed that the practice of family planning method is associated with the increase in age of the wives is similar to the finding of Oyedukun Amos 0 (2007) from Nigeria9 and Chakraborty N. et al (1993) from Bangladesh ${ }^{10}$.

An important finding in this study was that the total couple protection rate was low. Most of the couples did not use the family planning methods because they were unaware and uninformed about the use and availability of the various methods. They also wanted children and feared of the side effects.

The results of the present study that the reasons for not practicing any methods of family planning were lack of information in $22.89 \%$ of the couples, is somewhat similar to the results of Ram Rama et al(2000-01-2000-03) ${ }^{11}$

CONCLUSION: Sustained IEC efforts, motivation and education of the couples and easy availability of the family planning methods in the remote, un reached areas is expected to favour the acceptance of the methods by the rural tribal community in near future.

\section{REFERENCES:}

1. Census of India, 2001.

2. WHO(1971) Tech. Rep. Ser., No.442

3. Office of Registrar General of India.2001 census.

4. Mohanan Padma, Kamath Asha, Sajjan B.S. (2003) “Fertility Pattern And Family Planning Practices in a Rural Area of Dakshina Kannada". Indian Journal of Community Medicine. Vol. XXVIII, No.1, Jan-March.

5. Reddy Rajesh S., Premarajan K.C., Narayan K.A., Mishra Akshaya Kumar(2003) "Rapid Appraisal of Knowledge, Attitude and Practices related to Family Planning Methods Among Men Within 5 Years of Married Life." Indian J. Prev. Soc. Med Vol 34, No.1\&2 JanJune.pg 62-67 
6. Puri A., Garg S., Mehra M.,(2004) "Assessment of unmet need for contraception in an urban slum of Delhi." ." Indian Journal of Community Medicine. Vol XXIX, No.3, JulySeptember, 2004

7. Chandhick N., Dhillon B.S., Kambo I., Saxena NC.(2003) “Contraceptive Knowledge, Practices and Utilization of Services in the rural areas of India." (An ICMR Task Force Study). Vol. 57. Issue 7.pg 303-10

8. Aggarwal Hemla(2005) "Comparison of the Level of Awareness of Family Planning Measuresin the Urban and Urban-slum Women." Anthropologist, 7(1):35-40

9. Oyedukun Amos O.(2007), "Determinants of Contraceptive Usage: Lessons from women in Osun State, Nigeria." The Journal of Humanities \& Social Sciences ISSN 1934-7227. Volume 1, Issue 2.

10. Chakraborty Nitai, Ullah Md. Shahid (1993) "Factors Affecting The Use of Contraception in Bangladesh: A Multivariate Analysis.” Asia - Pacific Population Journal. Volume 8 No.3, pg 19-30

11. Ram Rama, Ghosh M.N., Bhattacharya Salil, Haldar Anima, Chatterjee Chitra, Naskar Narendranath (2000-01-2000-03) "Study of Unmet Need for Family Planning Among Married Women of Reproductive Age Attending Immunization Clinic in a Medical College of Calcutta." Indian Journal of Community Medicine. Volume 25. No. 1

Table 1. Distribution of the couples according to their status of practicing family planning methods:

\begin{tabular}{|l|l|l|}
\hline Status of Practice & Number & Percentage \\
\hline Approved methods & 90 & 29.70 \\
\hline Traditional methods & 12 & 3.96 \\
\hline Non practicing & 201 & 66.34 \\
\hline Total & 303 & 100 \\
\hline
\end{tabular}

Table 2: Distribution of the eligible couples according to specific family planning method adopted.

\begin{tabular}{|l|l|}
\hline Specific method & No $(\%)$ \\
\hline Condom & $3(2.94)$ \\
\hline Oral Contraceptive pills & $22(21.57)$ \\
\hline Intra Uterine Devices & $6(5.89)$ \\
\hline Tubectomy & $59(57.84)$ \\
\hline Vasectomy & 0 \\
\hline Safe Period & $12(11.76)$ \\
\hline Total & 102 \\
\hline
\end{tabular}


Table 3: Distribution of the husbands according to their literacy status and family planning method practiced by the couples.

\begin{tabular}{|l|l|l|l|}
\hline \multirow{2}{*}{ Literacy } & Practicing F.P & Non practicing F.P & Total \\
\cline { 2 - 4 } & No (\%) & No (\%) & No \\
\hline Illiterate & $2(15.38)$ & $11(84.62)$ & 13 \\
\hline Primary school & $8(61.54)$ & $5(38.46)$ & 13 \\
\hline Middle school & $17(47.22)$ & $19(52.78)$ & 36 \\
\hline $\begin{array}{l}\text { High school \& higher } \\
\text { education } \\
\text { graduation }\end{array}$ & $\begin{array}{r}\text { upto } \\
\text { Total }\end{array}$ & $161.12)$ & 241 \\
\hline
\end{tabular}

$\chi 2=9.21 ; p<0.05$

Table 4: Age of the wives and status of family planning practice

\begin{tabular}{|l|l|l|l|}
\hline Age in years & $\begin{array}{l}\text { Practicing } \\
\text { No (\%) }\end{array}$ & $\begin{array}{l}\text { Non practicing } \\
\text { No (\%) }\end{array}$ & Total \\
\hline $15-24$ & $11(23.40)$ & $36(76.60)$ & 47 \\
\hline $25-34$ & $63(35.59)$ & $114(64.41)$ & 177 \\
\hline $35-45$ & $28(35.44)$ & $51(64.56)$ & 79 \\
\hline Total & 102 & 201 & 303 \\
\hline
\end{tabular}

$\chi 2=16.55 ; \mathrm{p}<0.001$ 
Table 5: Distribution of eligible couples according to the reasons for never practicing F.P. methods

\begin{tabular}{|l|c|c|}
\hline \multirow{2}{*}{\multicolumn{1}{|c|}{}} & \multicolumn{2}{c|}{ Eligible couples } \\
\cline { 2 - 3 } Reasons & No & $\%$ \\
\hline Opposition from wife & - & - \\
\hline Husband's Opposition & - & - \\
\hline Lack of information & 46 & 22.89 \\
\hline Lack of knowledge & 37 & 18.41 \\
\hline Afraid of side effect & 42 & 20.90 \\
\hline Wants children & 45 & 22.38 \\
\hline Lacks interest & 31 & 15.42 \\
\hline Total & 201 & 100 \\
\hline
\end{tabular}

